Research Article

\title{
An Experimental Study on the Mechanical Properties of High-Temperature Granite under Natural Cooling and Water Cooling
}

\author{
Yanan Gao, ${ }^{1,2,3}$ Yunlong Wang, ${ }^{1,2}$ Taiping Lu, ${ }^{4}$ Liuzhou Li, ${ }^{5}$ Jinwen Wu $\left({ }^{6},{ }^{6}\right.$ \\ and Zetian Zhang $\mathbb{1}^{3}$ \\ ${ }^{1}$ State Key Laboratory for Geomechanics and Deep Underground Engineering, China University of Mining and Technology, \\ Xuzhou, Jiangsu 221116, China \\ ${ }^{2}$ School of Mechanics and Civil Engineering, China University of Mining and Technology, Xuzhou, Jiangsu 221116, China \\ ${ }^{3}$ Key Laboratory of Deep Earth Science and Engineering, Sichuan University, Chengdu, Sichuan 610025, China \\ ${ }^{4}$ School of Mechanics and Engineering, Southwest Jiaotong University, Chengdu, Sichuan 611756, China \\ ${ }^{5}$ Steel Structure Branch Co.,Ltd, CCCC Road and Bridge Construction, Beijing 100024, China \\ ${ }^{6}$ School of Science, North University of China, Taiyuan, Shanxi 030051, China
}

Correspondence should be addressed to Jinwen Wu; 20130001@nuc.edu.cn

Received 14 April 2021; Accepted 29 May 2021; Published 14 June 2021

Academic Editor: F. H. Samuel

Copyright (c) 2021 Yanan Gao et al. This is an open access article distributed under the Creative Commons Attribution License, which permits unrestricted use, distribution, and reproduction in any medium, provided the original work is properly cited.

With the further development of deep rock mechanics engineering, such as the exploitation and utilization of geothermal resources, the exploitation of deep mineral resources, and the safe disposal of nuclear waste, the study of mechanical properties of deep hightemperature rock is gaining the attention of the researchers. However, not only the high temperature but also the cooling condition/ method that will be used in the construction such as drilling cooling will also greatly affect the mechanical properties of the rock. In this paper, the mechanical behaviour and the evolution of the mechanical properties of the high-temperature $\left(600^{\circ} \mathrm{C}-1,000^{\circ} \mathrm{C}\right)$ granite under different cooling methods are studied. The following conclusions can be obtained: (1) The peak stress of the granite decreases with the heating temperature. Compared with natural cooling, water cooling has a more significant effect on strength degradation. (2) The increase of the heating temperature increases the maximum axial strain of the granite. The water cooling method more greatly induces the maximum axial strain of granite than the natural cooling. The maximum axial strain of the specimen under the water cooling reaches $117.3 \%$ of that under natural cooling $\left(800^{\circ} \mathrm{C}\right)$. (3) The elastic modulus of the granite decreases with the heating temperature. Water cooling will have a stronger effect on the reduction of the elastic modulus than natural cooling. The maximum difference value $(2.02 \mathrm{GPa})$ of the elastic modulus under the different cooling methods occurs at the temperature of $800^{\circ} \mathrm{C}$. (4) Poisson's ratio of the granite increases with heating temperature, and the cooling method does not have an evident effect on it. The relationship between Poisson's ratio and the heating temperature under different cooling methods can be described using the linear model. (5) According to the influence of the temperature on the peak stress, the elastic modulus, and Poisson's ratio, the heating temperature domain can be divided into the unapparent zone, the significant zone, and the mitigation zone. (6) The thermal stress due to the nonuniform temperature field and the different thermal expansion coefficients is incompatible. Such incompatibility stresses the essences of the degradation of the mechanical properties of the granite.

\section{Introduction}

In recent years, with the further development of deep rock mechanics engineering, such as the exploitation and utilization of geothermal resources, the exploitation of deep mineral resources, and the safe disposal of nuclear waste, the study of mechanical properties of the deep rock has gradually become an important research direction of rock mechanics [1-6]. For deep rock, the influence of temperature on the mechanical properties of the rock is very significant. 
The long-term effects of high temperatures affect the physical and mechanical properties of rocks, for example, uniaxial compressive strength, fracture characteristics, elastic modulus, and porosity [7, 8]. However, the deep hightemperature rock is often affected by different cooling modes under human activities and natural factors, and the deterioration of its mechanical properties will thus affect the stability or constructions of the engineering structure. Therefore, the study of the influence of different cooling methods on the mechanical properties of the high-temperature rock is necessary as it can provide a basis for the engineering design of deep rock engineering.

The mechanical properties of thermally treated rock have been a hot topic for decades. Oda obtained the change law and failure criterion of basic mechanical properties of rocks with temperature by studying some basic mechanical properties of rocks under the action of temperature [9]. Xu and Liu studied the variation rule of main mechanical parameters with temperature in uniaxial compression of granite under real-time high temperature $\left(20^{\circ} \mathrm{C}-600^{\circ} \mathrm{C}\right)$ and pointed out that $75^{\circ} \mathrm{C}$ and $200^{\circ} \mathrm{C}$ are the threshold temperatures for the significant changes of elastic modulus and uniaxial compressive strength of granite [10]. Dwivedi et al. studied thermomechanical properties, such as Young's modulus, uniaxial compressive strength, tensile strength, Poisson's ratio, coefficient of linear thermal expansion, and creep behaviour, of Indian granite at high temperatures in the range of $30^{\circ} \mathrm{C}-160^{\circ} \mathrm{C}[11]$. Hong et al. found that the physical properties of sandstone treated at high temperatures are greatly different from those treated at normal temperatures, and the difference is very significant when the treatment temperature is higher than $500^{\circ} \mathrm{C}$ [12]. Guo et al. carried out mode I three-point bending tests on a set of prenotched semicircular thermally treated granite specimens $\left(50^{\circ} \mathrm{C}-600^{\circ} \mathrm{C}\right)$ and identified the microcracking behaviour transition phenomenon as the thermal treatment temperature increases from $150^{\circ} \mathrm{C}$ - to $200^{\circ} \mathrm{C}$ based on the AE signals [13]. Moreover, many large-scale underground heating tests were conducted to study thermalmechanical behaviour in the rock mass, such as the Yucca Mountain drift scale test in America $[14,15]$.

Besides, the physical and mechanical properties of the high-temperature rock cooling with water are investigated widely. Zhu et al. carried out an experimental study on the physical and mechanical properties of thermally treated (room temperature $-500^{\circ} \mathrm{C}$ ) granite under the water cooling condition; the result shows that the physical and mechanical properties of water-cooled granite deteriorate with heating temperature. They also found that the specimens show an obvious ductility behaviour when the heating temperature reaches $300^{\circ} \mathrm{C}$ and above [16]. $\mathrm{Xi}$ and Zhao studied the mechanical properties of high-temperature $\left(<600^{\circ} \mathrm{C}\right)$ granites cooled by water and discussed the mechanism of hydrothermal fracture degradation [17]. In addition, the study of the mechanical properties of high-temperature rock with the consideration of the different cooling methods is not carried out very much. Rathnaweera et al. investigated the effects of temperature $\left(25^{\circ} \mathrm{C}-1,000^{\circ} \mathrm{C}\right)$ and two subsequent cooling methods (fast and slow) on the mechanical behaviour of the clay-rich Hawkesbury sandstone under uniaxial conditions [18] and pointed out that progressive dehydroxylization of kaolinite in the sandstone cement at temperatures beyond $600^{\circ} \mathrm{C}$ was found to be the main reason for the weakening and softening of the sandstone. Zhang et al. studied the influence of cooling rate on physical and mechanical properties of thermally treated granite and found that the high cooling rate induces important thermal stresses, and it will induce a significant change of mechanical properties [19].

Most of the above studies are conducted on natural cooling or water cooling separately on the rock, while there are few comparative analyses of natural cooling and water cooling. In this paper, uniaxial compression experiments are carried out on the high-temperature $\left(600^{\circ} \mathrm{C}-1,000^{\circ} \mathrm{C}\right)$ granite that experienced different cooling methods (natural cooling and water cooling). The evolution of the elastic modulus, Poisson's ratio, and the peak stress of granite with temperature under two cooling modes is investigated. The influences on the mechanical properties of the two mentioned cooling methods different are compared and discussed.

\section{Specimen Preparation and Test Processes}

2.1. Specimen Preparation. The granite samples are collected from Pingyi, Shandong Province. The granite is greywhite, compact, and crack-free. Firstly, the cylindrical granite specimen of $\Phi 50 \mathrm{~mm} \times 100 \mathrm{~mm}$ is processed from the whole rock using water drilling, and then the specimen is polished to make its size and precision in accordance with the standard of ISRM (International Society for Rock Mechanics) [20]. In this experiment, a total of 20 granite specimens are prepared. Some of the specimens are shown in Figure 1. The specimens are equally divided into 5 heating groups ( 4 in each group). Then the specimens are put into the heating furnace for thermal treatment. The heating rate is about $1^{\circ} \mathrm{C} / \mathrm{min}$ to avoid the impact of thermal shock. The target temperatures are $600^{\circ} \mathrm{C}, 700^{\circ} \mathrm{C}$, $800^{\circ} \mathrm{C}, 900^{\circ} \mathrm{C}$, and $1,000^{\circ} \mathrm{C}$. When the target temperature is reached, the temperature will remain for 3 hours. For the water cooling condition, 2 specimens of each group are put into distilled water $\left(25^{\circ} \mathrm{C}\right)$ for a 24 -hour cooling. For the natural cooling condition, the other 2 specimens are left in the furnace chamber for 8-hour cooling. After the cooling process, the 5 groups of specimens are divided into 10 groups, with the consideration of the cooling method (Table 1).

The terminology of the specimens is as follows: the first two numbers represent the heating temperature (06 denotes $600^{\circ} \mathrm{C}, 07$ denotes $700^{\circ} \mathrm{C}, 08$ denotes $800^{\circ} \mathrm{C}$, and so on). The third number represents the cooling methods ( 1 denotes the water cooling method, and 2 denotes the natural cooling method). The last number is the order of each testing condition. For example, the "0812" represents the second specimen, which is heated to $800^{\circ} \mathrm{C}$ and experienced water cooling. 

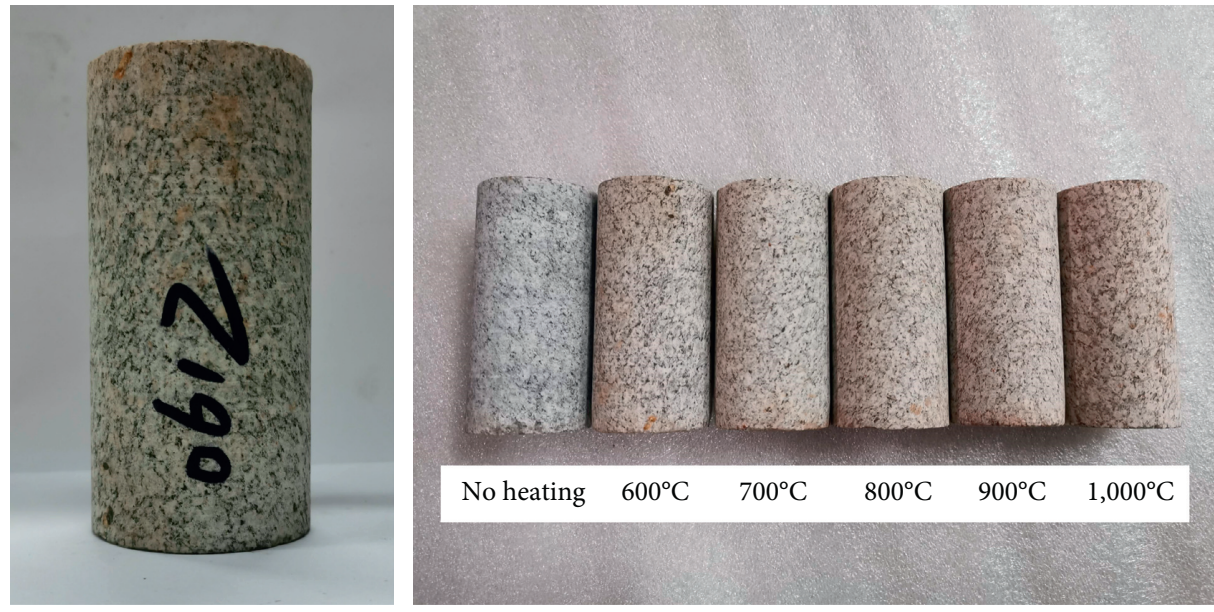

FIGURE 1: Rock specimens.

TABLE 1: Specimen number scheme.

\begin{tabular}{lcc}
\hline \multirow{2}{*}{ Heating temperature $\left({ }^{\circ} \mathrm{C}\right)$} & \multicolumn{2}{c}{ Specimen number } \\
& Water cooling & Natural cooling \\
\hline \multirow{2}{*}{600} & 0612 & 0623 \\
& 0614 & 0625 \\
700 & 0712 & 0721 \\
& 0714 & 0723 \\
800 & 0814 & 0821 \\
& 0812 & 0824 \\
900 & 0914 & 0923 \\
\multirow{2}{*}{1,000} & 0915 & 0925 \\
& 1011 & 1023 \\
\hline
\end{tabular}

2.2. Experimental Methods. The facility used in the experiment mainly includes two parts: the test loading system and the data acquisition system (Figure 2). The loading system is a microcomputer-controlled electronic machine. The model is WDWE200, and the maximum load is $200 \mathrm{kN}$. The strain acquisition system is a DH3820 high-speed strain acquisition system. The sampling frequency is $50 \mathrm{~Hz}$. The strain sensors are strain gauges with the size of $5 \mathrm{~mm} \times 3 \mathrm{~mm}$. The strain sensors and the strain acquisition are connected with the $1 / 4$ bridge converter. Moreover, the strain sensor for temperature compensation is adopted.

The test procedures are as follows:

(1) Set up the deformation sensors

(2) Position the specimen into loading space

(3) Apply the preloading of $0.12 \mathrm{kN}$ on the specimen

(4) Apply the loading under the displacement control model $(0.1 \mathrm{~mm} / \mathrm{min})$

(5) Stop loading process when the specimen failures

(6) Take a photo of the failure pattern for each specimen (Figure 3)

The data of axial displacement, axial load, and lateral strain are recorded using a microcomputer-controlled testing machine and high-speed strain acquisition system separately for further analysis.

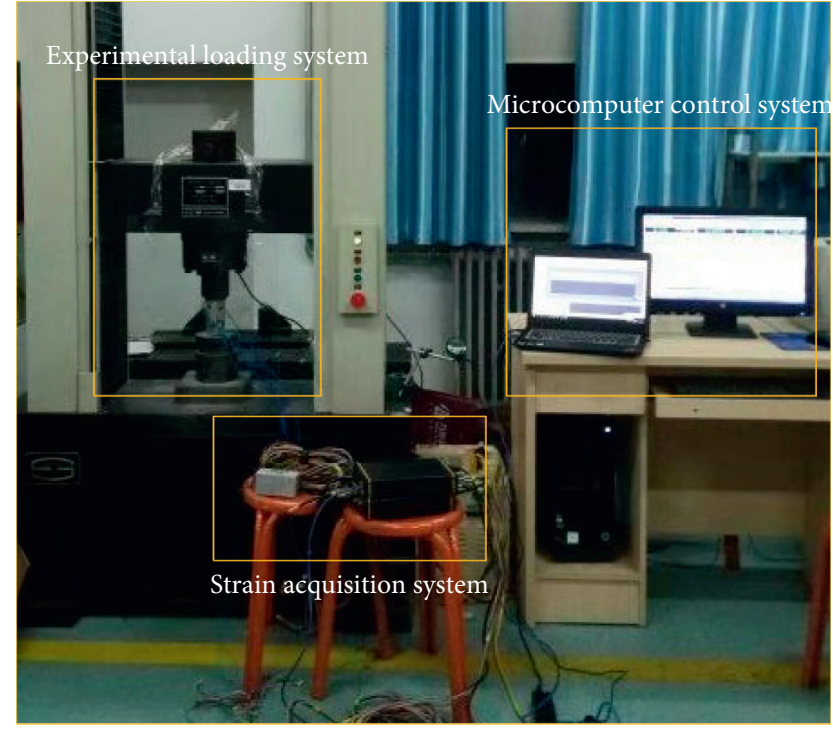

FIgURE 2: Testing facility.

\section{Experimental Results and Analysis}

This section describes the results and analysis of the hightemperature granite under two cooling methods. The effects of the heating temperature and the cooling methods on the mechanical properties of the granite are presented and explained. Based on Figure 3, it can be found that the level of complexity increases with the heating temperature under the same cooling method. On the other hand, compared with the natural cooling method, the water cooling method may result in a higher level of complexity for a constant heating temperature.

3.1. Stress-Strain Curve Analysis. The stress-strain curve is one of the important indexes reflecting the mechanical properties of the rocks. The stress-strain curve is composed of three parts: (1) stress-axial strain part, (2) stress-circumferential strain part, and (3) stress-volume strain part. Figure 4 is a comparison of the stress-strain curves of natural 


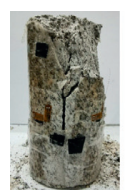

0612

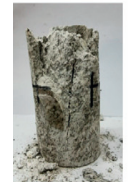

0623

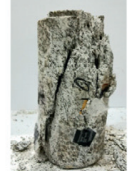

0614

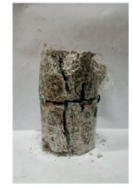

0625

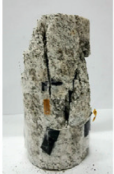

0712

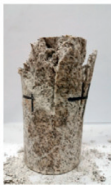

0721

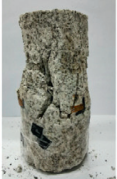

0714

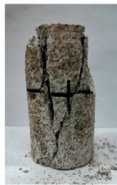

0723

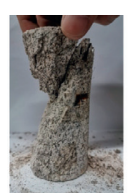

0812

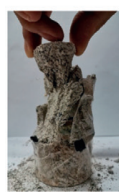

0821

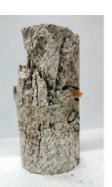

0814

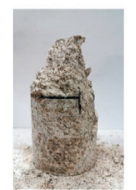

0824

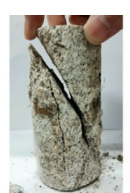

0914

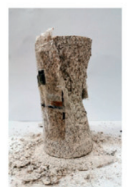

0923

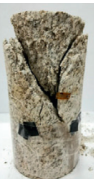

0915

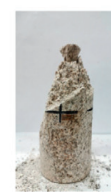

0925

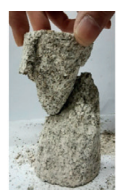

1011

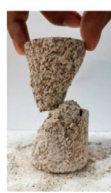

1023

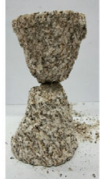

1014

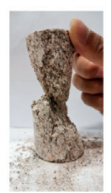

1024

FIGURE 3: Failure patterns of the specimens.

cooling and water cooling under different heating temperatures. In Figure 4, the curve in red represents the stressstrain curve of the specimens cooled by water (WC), while the curve in black represents the stress-strain curve of the specimens cooled naturally (NC). $\varepsilon_{x}, \varepsilon_{y}$, and $\varepsilon_{v}$ denote the circumferential strain, the axial strain, and the volume strain, respectively.

Based on Figure 4, it can be found that the stress-strain curve of the specimen can be divided into four parts according to the stress-axial strain part (Figure 5) under each cooling method: (1) compaction part, (2) elastic part, (3) plastic deformation part, and (4) postfailure part.

By comparing the stress-strain curves of the specimens under different heating temperatures in Figure 4, it can be found that the maximum axial strain of the water cooling specimens is generally greater than that of natural cooling. It indicates that the water cooling method may eliminate the brittleness and increase the ductility for the high-temperature granite. The peak stress of the water cooling specimens is generally lower than that of the natural cooling specimens. Thus, it can be concluded that the water cooling method will cause a loss of the bearing capacity of the high-temperature granite.

3.2. Peak Stress Analysis. The peak stress of the granite under uniaxial compression can directly reflect the strength of the specimen and is the primary basis for design and analysis in engineering practice. The peak stress value of each specimen is obtained from the top point of the stress-strain curve.

The peak stress data of the 20 specimens under two different cooling methods in each temperature level are summarized in Table 2, and Figure 6 is the variation of peak stress of specimen with different temperature under two different cooling methods. The peak stress of the natural cooling specimen minus that of the water cooling specimen in each heating temperature level is the difference value illustrated in Figure 6.

Figure 6 shows that regardless of the cooling method, the peak stress generally decreases with the heating temperature. However, the influence of different cooling methods on the peak stress is clearly associated with the heating temperature. The peak stress of the natural cooling specimen in the range of $700^{\circ} \mathrm{C}-900^{\circ} \mathrm{C}$ is obviously higher than that of the water cooling specimen. When the heating temperature is $1,000^{\circ} \mathrm{C}$, the peak stress values under the two cooling methods are close. Only at $600^{\circ} \mathrm{C}$, the peak stress of the natural cooling specimen is less than that of the water cooling specimen. Therefore, the plot of Figure 6 can be divided into three zones. (1) unapparent zone $\left(600^{\circ} \mathrm{C}-700^{\circ} \mathrm{C}\right)$ : in this zone, the influence of cooling method on the peak stress is not significant, (2) significant zone $\left(700^{\circ} \mathrm{C}-900^{\circ} \mathrm{C}\right)$ : the difference of the peak stress between the specimen under the different cooling methods increases with the temperature in this zone, and (3) mitigation zone $\left(900^{\circ} \mathrm{C}-1,000^{\circ} \mathrm{C}\right)$ : the peak stress values under the different cooling methods come close in this zone.

Therefore, it is generally believed that the peak strength of the high-temperature $\left(700^{\circ} \mathrm{C}-900^{\circ} \mathrm{C}\right)$ granite under the water cooling condition will decrease significantly compared with natural cooling granite, and the cooling methods have little effect on peak stress after $900^{\circ} \mathrm{C}$.

3.3. Maximum Axial Strain Analysis. The maximum strain can reflect the deformability of the rock. Thus, it is also practical and important to investigate the maximum axial strain [21]. Table 3 lists the peak strain of the specimens under each condition. Moreover, Figure 7 shows the comparison of peak strain values under different cooling methods.

Firstly, it can be observed that no matter which cooling method is used, the maximum axial strain of the specimen increases with the heating temperature. It means that the higher the heating temperature, the greater the ductility of the specimen. In other words, the larger deformation is when the high-temperature rock mass is loaded.

This can also be clearly seen in Figure 7 that the peak strain of the water cooling specimen is significantly higher than that under the natural cooling specimen. At the temperature of $800^{\circ} \mathrm{C}$, the maximum axial strain of the specimen under the water cooling reaches $117.3 \%$ of that under natural cooling. When the heating temperature is $600^{\circ} \mathrm{C}$ or $1,000^{\circ} \mathrm{C}$, the difference value of the maximum axial strain of the specimens under the different cooling methods is relatively small. Nevertheless, the maximum axial strain of the specimen under the water cooling still reaches $110 \%$ as under the natural cooling at the same heating temperature. According to 

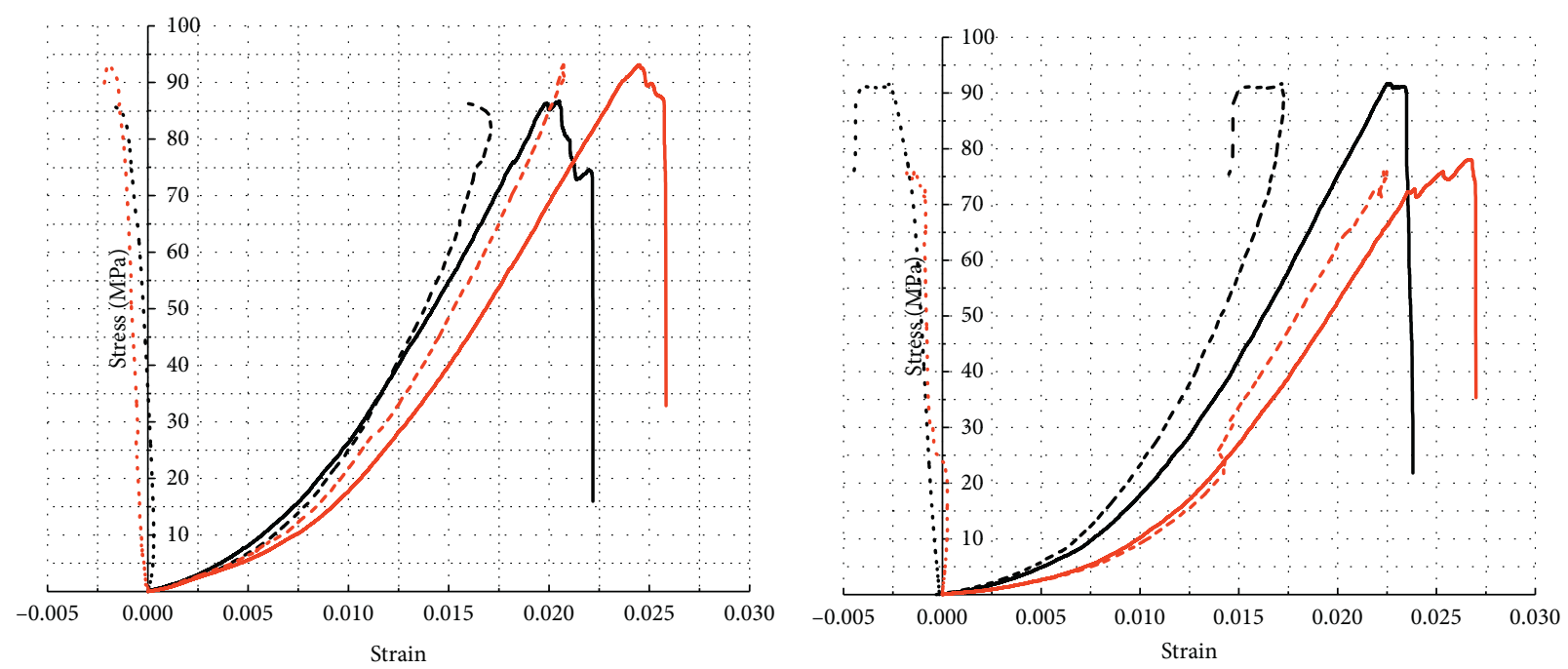

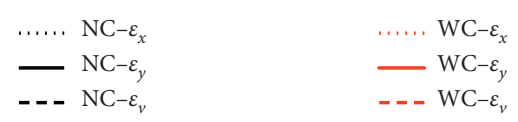

(a)

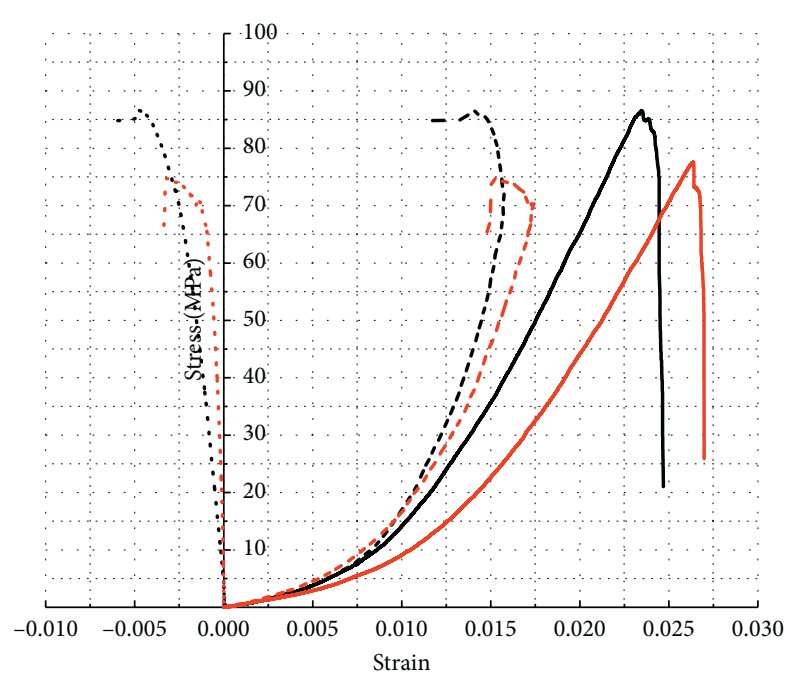

.... $\mathrm{NC}-\varepsilon_{x}$
$\mathrm{NC}-\varepsilon_{y}$
$-2 \mathrm{NC}-\varepsilon_{v}$
......WC- $-\varepsilon_{x}$

- $\mathrm{WC}-\varepsilon_{y}$

(c) $\ldots . .$.
$-\mathrm{NC}-\varepsilon_{x}$
$-\mathrm{NC}-\varepsilon_{y}$

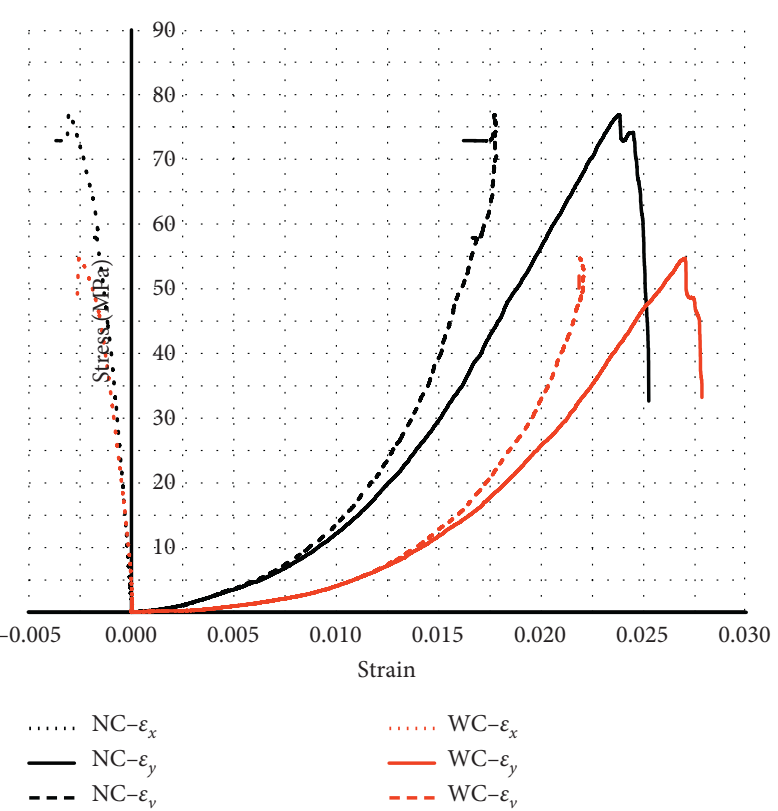

(d)

Figure 4: Continued. 


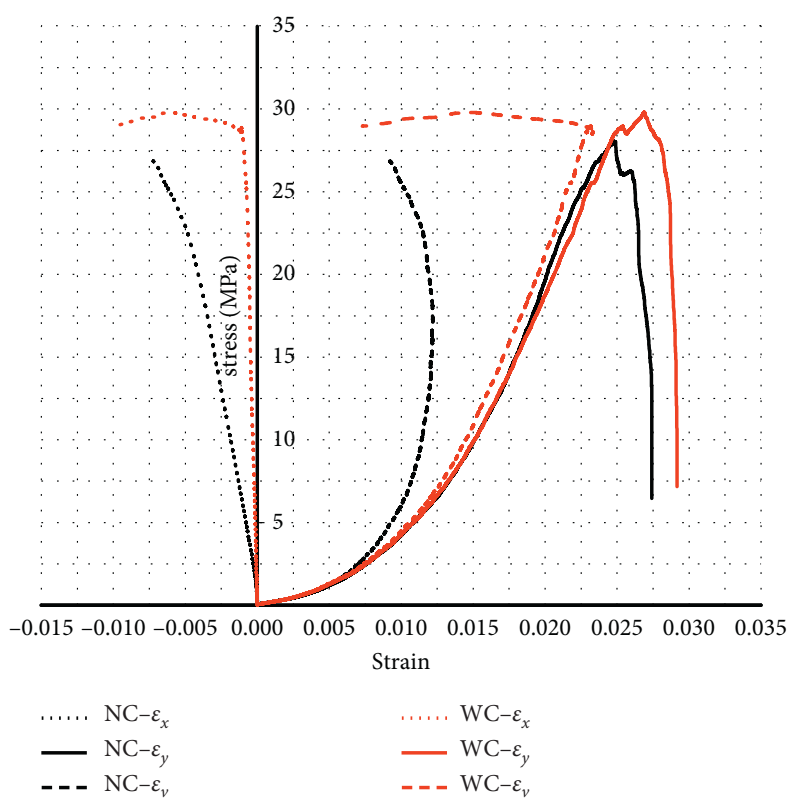

(e)

Figure 4: Comparison of stress-strain curves of natural cooling (NC) and water cooling (WC) at different temperatures: (a) $600^{\circ} \mathrm{C}(0625$ and 0614), (b) $700^{\circ} \mathrm{C}$ (0721 and 0712), (c) $800^{\circ} \mathrm{C}(0824$ and 0812$)$, (d) $900^{\circ} \mathrm{C}(0923$ and 0915$)$, and (e) $1,000^{\circ} \mathrm{C}(1023$ and 1014$)$.

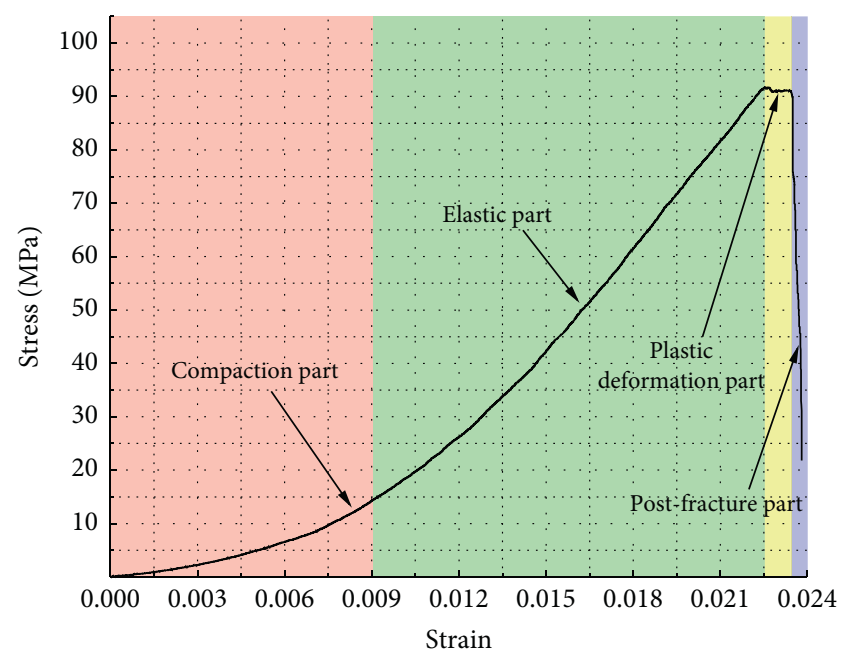

FIgURE 5: The stress-strain curve (0721).

the theory of the maximum positive strain strength, compared with natural cooling, the mechanical properties of the water cooling specimen are evidently decreased. It also shows that the deformability of the high-temperature granite is enhanced after being cooled by water, that is, this cooling method can give the rock ability of more deformation. In addition, it indicates that the influence of the cooling method on granitic deformation should be taking into consideration for hightemperature-associated engineering.

3.4. Elastic Modulus Analysis. Elastic modulus is a basic parameter of materials that can reflect the ability to resist deformation and the stiffness of rock. Thus, the evolution of such a parameter is necessary to be studied. Table 4 summarizes the elastic modulus data of all specimens. Figure 8 is the plot of the elastic modulus of the specimens under each condition. The elastic modulus of the natural cooling specimen minus that of the water cooling specimen in each heating temperature level is the difference value illustrated in Figure 8 .

According to Figure 8, the elastic modulus decreases with the heating temperature under each cooling method. Moreover, this phenomenon implies that thermal treatment will reduce the stiffness of the granite and its resistance to deformation even if the granite is cooled. Furthermore, according to the difference value in Figure 8, the plot can be divided into three zones: (1) unapparent zone $\left(600^{\circ} \mathrm{C}-700^{\circ} \mathrm{C}\right)$ : in this zone, the influence of cooling method on the elastic modulus is not significant, (2) significant zone $\left(700^{\circ} \mathrm{C}-900^{\circ} \mathrm{C}\right)$ : the difference of the elastic modulus between the specimen under the different cooling methods increases with the temperature in this zone, and (3) mitigation zone $\left(900^{\circ} \mathrm{C}-1,000^{\circ} \mathrm{C}\right)$ : the elastic modulus values under the different cooling methods come close in this zone.

The elastic modulus decreases more dramatically under the water cooling method in the significant zone. Between $700^{\circ} \mathrm{C}$ and $900^{\circ} \mathrm{C}$, the decline of the elastic modulus of the specimen under the water cooling method is much sharper than that under natural cooling. During this range, the elastic modulus reduces from $5.57 \mathrm{GPa}$ to $3.78 \mathrm{GPa}$ under the water cooling condition, and it decreases from $6.54 \mathrm{GPa}$ to $5.29 \mathrm{GPa}$ under the natural cooling condition. The difference between the two different cooling methods is $>1 \mathrm{GPa}$. It is noteworthy that the maximum difference value $(2.02 \mathrm{GPa})$ occurs at the temperature of $800^{\circ} \mathrm{C}$. 
TABLE 2: Experimental results of peak stress.

\begin{tabular}{lccc}
\hline Specimen number & Peak stress $(\mathrm{MPa})$ & Specimen number & Peak stress $(\mathrm{MPa})$ \\
\hline 0612 & 78.86 & 0623 & 67.76 \\
0614 & 93.29 & 0625 & 86.64 \\
0712 & 78.14 & 0721 & 91.70 \\
0714 & 85.39 & 0723 & 89.64 \\
0814 & 54.57 & 0821 & 74.72 \\
0812 & 77.58 & 0824 & 86.58 \\
0914 & 39.62 & 0923 & 76.86 \\
0915 & 54.61 & 0925 & 62.44 \\
1011 & 36.26 & 1023 & 28.32 \\
1014 & 29.85 & 1024 & 28.90 \\
\hline
\end{tabular}

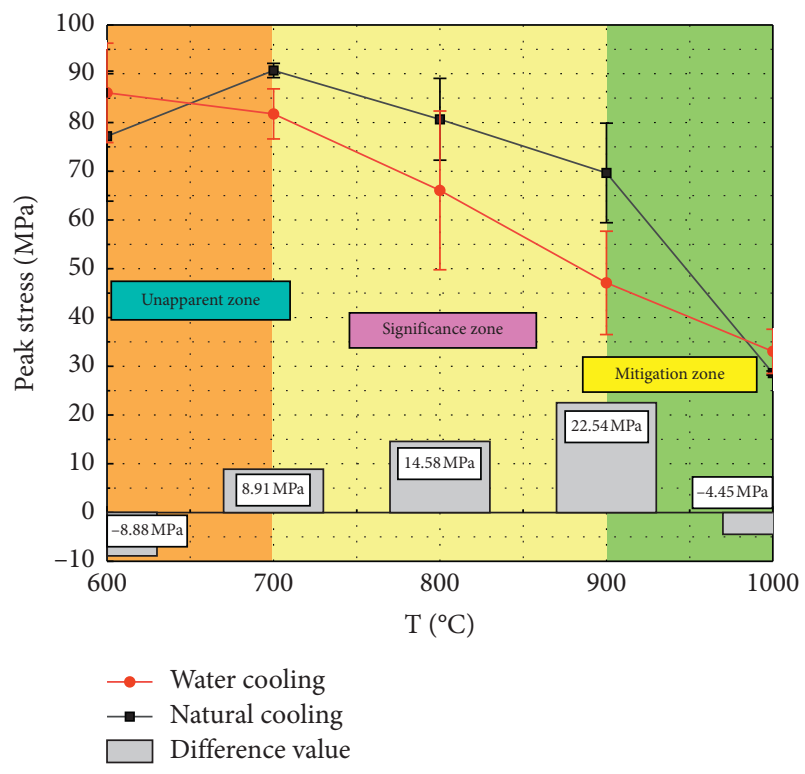

Figure 6: Comparison of peak stress of two different cooling methods.

Based on Figure 8, it can also be found that from $600^{\circ} \mathrm{C}$ to $800^{\circ} \mathrm{C}$, the influence of the cooling method on the elastic modulus aggravates with the increasing temperature. However, the effect of the cooling method on the elastic modulus gradually mitigates when the temperature exceeds $800^{\circ} \mathrm{C}$. This phenomenon may be due to the great change in porosity of the granite under the high temperature of $800^{\circ} \mathrm{C}$ as the ultra-micropores begin to transform to the micropores in this situation [22].

3.5. Poisson's Ratio Analysis. Poisson's ratio, as an elastic parameter describing the elastic behaviour of a material, can reflect the lateral deformation of a material in the process of stretching or compression. Poisson's ratio plays an important role in well drilling and completion, deep formation fracturing design, and so on and is a vital parameter in fracture pressure estimation methods. The results of Poisson's ratio are listed in Table 5. Poisson's ratio of the natural cooling specimen minus that of the water cooling specimen in each heating temperature level is the difference value illustrated in Figure 9. The relationship between Poisson's ratio and the heating temperature under different cooling methods can be described using the linear model.

In Figure 9, it can be found that Poisson's ratio always has an increasing trend, except for a slight drop of $700^{\circ} \mathrm{C}-800^{\circ} \mathrm{C}$ under the water cooling condition. For the natural cooling condition, Poisson's ratio increases slowly with temperature from $600^{\circ} \mathrm{C}$ to $800^{\circ} \mathrm{C}$, drops slightly at $900^{\circ} \mathrm{C}$, and then increases rapidly.

At present, there are two points of view about the influence of the temperature on Poisson's ratio of rock. Some scholars insisted that Poisson's ratio is not directly related to temperature [23]. On the other hand, Poisson's ratio is deemed variable with temperature. For example, Du pointed out that Poisson's ratio showed a decreasing trend with the increase of temperature [24], while $\mathrm{Xu}$ and Liu drew the conclusion that Poisson's ratio increased with the temperature [10]. According to the trend and linear fitting (Figure 9), it can be seen that Poisson's ratio obtained in this study has a clear correlation with the temperature, that is, it generally increases with the increase of temperature under each cooling method.

As shown in Figure 9, the influence on Poisson's ratio of the cooling method can be divided into three zones: (1) unapparent zone $\left(600^{\circ} \mathrm{C}-800^{\circ} \mathrm{C}\right)$ : in this zone, the influence of the cooling method on Poisson's ratio is not significant, (2) significant zone $\left(800^{\circ} \mathrm{C}-900^{\circ} \mathrm{C}\right)$ : the difference of Poisson's ratio between the specimen under the different cooling methods increases with the temperature in this zone, and (3) mitigation zone $\left(900^{\circ} \mathrm{C}-1,000^{\circ} \mathrm{C}\right)$ : Poisson's ratio values under the different cooling methods come close in this zone. Moreover, the parameters of the linear fitting equations of the different cooling methods are very close. Therefore, it can be concluded that the cooling method has no significant effect on the trend of Poisson's ratio but the influence on Poisson's ratio of each cooling method can be divided into three zones.

\section{Discussion}

The above study obtained the evolution of the mechanical properties of the granite under different conditions (heating temperature and cooling method) based on the experiment data. In this section, these phenomena or the causes will be discussed. 
TABLE 3: Experimental results of maximum axial strain.

\begin{tabular}{lccc}
\hline Specimen number & Maximum axial strain & Specimen number & Maximum axial strain \\
\hline 0612 & 0.0248 & 0623 & 0.0222 \\
0614 & 0.0258 & 0625 & 0.0241 \\
0712 & 0.0270 & 0721 & 0.0238 \\
0714 & 0.0279 & 0723 & 0.0257 \\
0814 & 0.0289 & 0821 & 0.0247 \\
0812 & 0.0270 & 0824 & 0.0229 \\
0914 & 0.0294 & 0923 & 0.0251 \\
0915 & 0.0278 & 0925 & 0.0252 \\
1011 & 0.0309 & 1023 & 0.0274 \\
1014 & 0.0292 & 1024 & 0.0273 \\
\hline
\end{tabular}

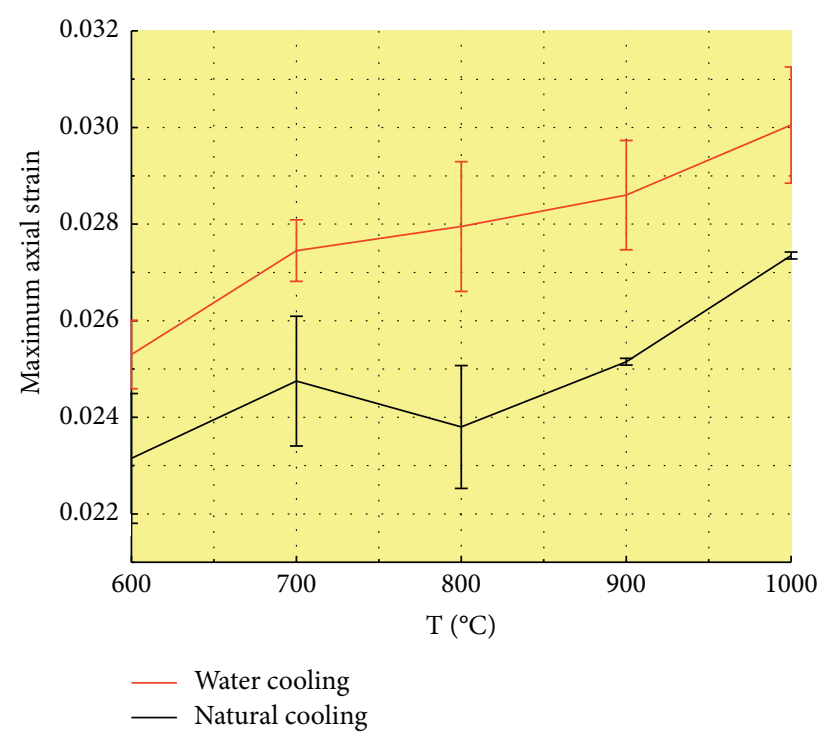

FIgURE 7: Comparison of maximum axial strain of two different cooling methods.

TABLE 4: Experimental results of elastic modulus.

\begin{tabular}{lccc}
\hline Specimen number & Elastic modulus $(\mathrm{GPa})$ & Specimen number & Elastic modulus $(\mathrm{GPa})$ \\
\hline 0612 & 6.36 & 0623 & 4.52 \\
0614 & 6.14 & 0625 & 6.39 \\
0712 & 5.69 & 0721 & 6.71 \\
0714 & 5.45 & 0723 & 6.37 \\
0814 & 5.17 & 0821 & 6.33 \\
0812 & 3.44 & 0824 & 6.33 \\
0914 & 3.10 & 0923 & 5.65 \\
0915 & 4.46 & 0925 & 4.92 \\
1011 & 2.57 & 1023 & 2.34 \\
1014 & 2.07 & 1024 & 2.32 \\
\hline
\end{tabular}

The influence zone and the maximum difference of each parameter are listed in Table 6. The unapparent zone, significance zone, and mitigation zone of the peak stress and elastic modulus are the same, and they are $600^{\circ} \mathrm{C}-700^{\circ} \mathrm{C}$, $700^{\circ} \mathrm{C}-900^{\circ} \mathrm{C}$, and $900^{\circ} \mathrm{C}-1,000^{\circ} \mathrm{C}$, respectively,. On the other hand, the unapparent zone, significance zone, and mitigation zone of Poisson's ratio is $600^{\circ} \mathrm{C}-800^{\circ} \mathrm{C}, 800^{\circ} \mathrm{C}-900^{\circ} \mathrm{C}$, and $900^{\circ} \mathrm{C}-1,000^{\circ} \mathrm{C}$, respectively. The difference of the peak stress or Poisson's ratio increases with the temperature during the significance zone, while the difference of the elastic modulus increases firstly with the temperature and decreases after the turning point of $800^{\circ} \mathrm{C}$.

Initially, the main difference of the effect on mechanical properties of the granite under the different cooling methods is that the water cooling will produce large thermal impact stress inside the granite [25], which will cause the granite to undergo thermal cracking. Moreover, the high-temperature heating process will change the composition and microstructure of the granite [26] as the granite is composed of multiple mineral grains, which is 


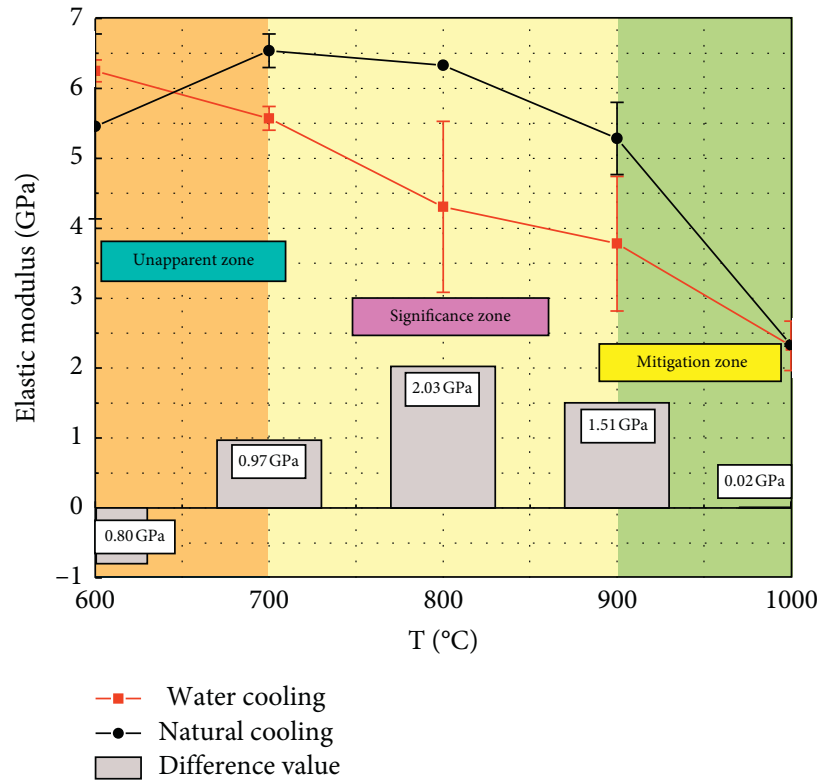

Figure 8: Comparison of elastic modulus of two different cooling methods.

TABle 5: Experimental results of Poisson's ratio.

\begin{tabular}{lccc}
\hline Specimen number & Poisson's ratio & Specimen number & Poisson's ratio \\
\hline 0612 & 0.099 & 0623 & 0.054 \\
0614 & 0.091 & 0625 & 0.143 \\
0712 & 0.183 & 0721 & 0.214 \\
0714 & 0.138 & 0723 & 0.143 \\
0814 & 0.106 & 0821 & 0.086 \\
0812 & 0.152 & 0824 & 0.370 \\
0914 & 0.421 & 0923 & 0.273 \\
0915 & 0.484 & 0925 & 0.116 \\
1011 & 0.567 & 1023 & 0.696 \\
1014 & 0.429 & 1024 & 0.484 \\
\hline
\end{tabular}

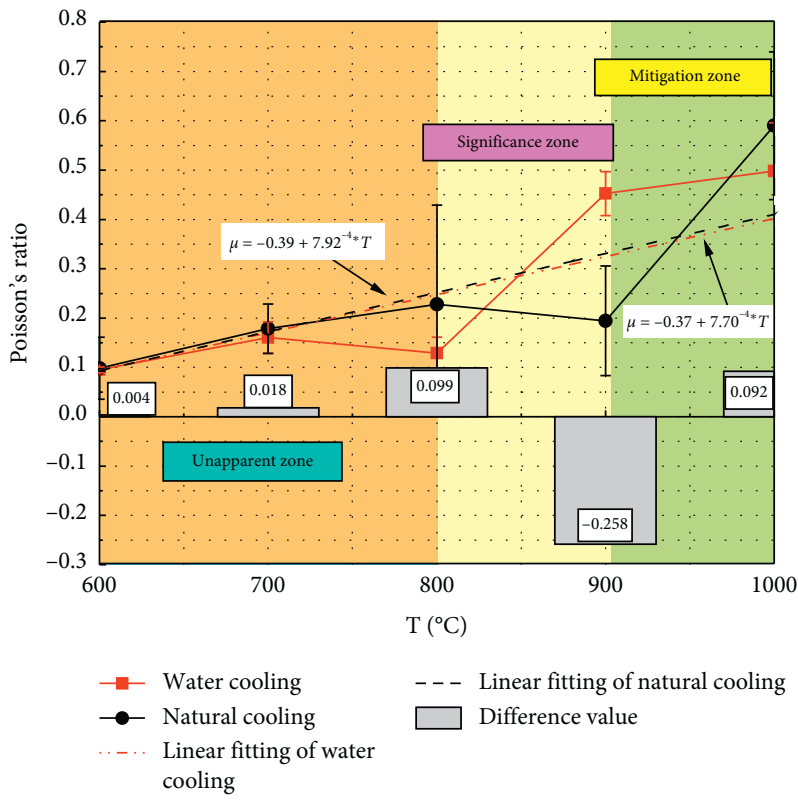

FIGURE 9: Poisson's ratio under the different cooling methods. 
TABLE 6: Summary of the influence zone and maximum difference.

\begin{tabular}{|c|c|c|c|c|}
\hline \multirow{2}{*}{ Parameters } & \multicolumn{4}{|c|}{ Influence zone } \\
\hline & Unapparent zone & Significance zone & Mitigation zone & Max. difference and the temperature \\
\hline Peak stress & $600^{\circ} \mathrm{C}-700^{\circ} \mathrm{C}$ & $700^{\circ} \mathrm{C}-900^{\circ} \mathrm{C}$ & $900^{\circ} \mathrm{C}-1,000^{\circ} \mathrm{C}$ & $22.54 \mathrm{MPa}, 900^{\circ} \mathrm{C}$ \\
\hline E & $600^{\circ} \mathrm{C}-700^{\circ} \mathrm{C}$ & $700^{\circ} \mathrm{C}-900^{\circ} \mathrm{C}$ & $900^{\circ} \mathrm{C}-1,000^{\circ} \mathrm{C}$ & $2.03 \mathrm{GPa}, 800^{\circ} \mathrm{C}$ \\
\hline$\mu$ & $600^{\circ} \mathrm{C}-800^{\circ} \mathrm{C}$ & $800^{\circ} \mathrm{C}-900^{\circ} \mathrm{C}$ & $900^{\circ} \mathrm{C}-1,000^{\circ} \mathrm{C}$ & $0.258,900^{\circ} \mathrm{C}$ \\
\hline
\end{tabular}

very sensitive to temperature. During the heating process, different mineral grains have different thermal expansion coefficients; thus, the original structure will inevitably be destroyed, and microcracks will occur. This is also in agreement with $\mathrm{Wu}$ et al. who found that a high cooling rate will cause not only intergranular cracks but also intragranular cracks in the rock samples [27]. In addition, the crystallization water will also volatilize in the heating process, which will cause the formation of the microcracks inside the granite. After being cooled by water, due to the low thermal conductivity of the rock, the heat cannot be transferred to the whole structure immediately. Therefore, the nonuniform temperature field may form in the specimen. Meanwhile, the thermal expansion coefficient varies for different kind of mineral grains. The thermal stress that is caused by the temperature will be very complicated and incompatible. Thus, the cracks induced by the thermal stress may initiate and propagate. The phenomena and process mentioned above may result in lower peak stress and elastic modulus and a higher maximum strain of the granite than those under natural cooling.

\section{Conclusions}

In this paper, a uniaxial compression test is carried out to study the failure behaviour in thermally treated granite $\left(600^{\circ} \mathrm{C}-1,000^{\circ} \mathrm{C}\right)$ under different cooling conditions. The influence of the cooling method on the evolution of the mechanical properties of the granite is investigated. The conclusions can be generated as follows:

(1) The peak stress of the granite decreases with the heating temperature. Compared with natural cooling, water cooling has a more significant effect on strength degradation.

(2) The increase of heating temperature increases the maximum axial strain of the granite. Water cooling more greatly induces the increase of the maximum axial strain of granite than natural cooling. The maximum axial strain of the specimen under the water cooling reaches $117.3 \%$ of that under natural cooling $\left(800^{\circ} \mathrm{C}\right)$.

(3) The elastic modulus of the granite decreases with the heating temperature. In the range of $700^{\circ} \mathrm{C}-900^{\circ} \mathrm{C}$, the cooling method affects the elastic modulus remarkably. The water cooling method has a stronger effect on the reduction of the elastic modulus than natural cooling. The maximum difference value $(2.02 \mathrm{GPa})$ of the elastic modulus under the different cooling methods occurs at the temperature of $800^{\circ} \mathrm{C}$.
(4) Poisson's ratio of the granite increases with the heating temperature, and the cooling method does not have an evident effect on it. The relationship between Poisson's ratio and the heating temperature under different cooling methods can be described using the linear model. The parameters of the linear models of the different cooling methods are also quite close.

(5) The heating temperature can be divided into three regions in term of its influence on the peak stress, the elastic modulus, and Poisson's ratio, that is, the unapparent zone, the significant zone, and the mitigation zone. The unapparent zone, significance zone, and mitigation zone of the peak stress and elastic modulus are the same, and they are $600^{\circ} \mathrm{C}-700^{\circ} \mathrm{C}, 700^{\circ} \mathrm{C}-900^{\circ} \mathrm{C}$, and $900^{\circ} \mathrm{C}-1,000^{\circ} \mathrm{C}$, respectively. On the other hand, the unapparent zone, significance zone, and mitigation zone of Poisson's ratio is $600^{\circ} \mathrm{C}-800^{\circ} \mathrm{C}, 800^{\circ} \mathrm{C}-900^{\circ} \mathrm{C}$, and $900^{\circ} \mathrm{C}-1,000^{\circ} \mathrm{C}$, respectively.

(6) The thermal stress, caused by the nonuniform temperature field that is induced by the cooling method and the thermal expansion coefficients of different mineral grains, is incompatible. Such incompatible stress may result in the degradation of the mechanical properties (peak stress, elastic modulus, and maximum strain) of the granite, especially under the water cooling condition.

\section{Notations}

$\varepsilon_{x}: \quad$ Circumferential strain

$\varepsilon_{y}: \quad$ Axial strain

$\varepsilon_{v}$ : Volume strain

T: $\quad$ Temperature ${ }^{\circ} \mathrm{C}$

E: Elastic modulus

$\mu$ : Poisson's ratio

NC: Natural cooling

WC: Water cooling.

\section{Data Availability}

The data used to support the findings of this study are available from the first author upon request.

\section{Conflicts of Interest}

The authors declare that they have no conflicts of interest. 


\section{Acknowledgments}

This project was supported by the National Natural Science Foundation of China (Nos. 52078477, 51504220, and 51827901) and Key Laboratory of Deep Earth Science and Engineering, Ministry of Education (DESE202106 and DESE202004). The authors acknowledge the supports of the above-mentioned funding agencies.

\section{References}

[1] H. Xie, H. Zhou, D. Xue, and H. Wang, "Research and consideration on deep coal mining and critical mining depth," Journal of China Coal Society, vol. 37, no. 4, pp. 535-542, 2013.

[2] M. He, "Conception system and evaluation indexes for deep engineering," Chinese Journal of Rock Mechanics and Engineering, vol. 25, no. 16, pp. 2854-2858, 2005.

[3] M. Gao, M. Wang, J. Xie et al., "In-situ disturbed mechanical behavior of deep coal rock," Journal of China Coal Society, vol. 45, no. 8, pp. 2691-2703, 2020.

[4] X. Hao, W. Du, Y. Zhao et al., "Dynamic tensile behaviour and crack propagation of coal under coupled static-dynamic loading," International Journal of Mining Science and Technology, vol. 30, no. 5, pp. 659-668, 2020.

[5] Y. Gao, L. N. Y. Wong, and F. Gao, "Finite deformation analysis on sandstone subjected to thermo-hydro-mechanical (T-H-M) coupling," Rock Mechanics and Rock Engineering, vol. 48, no. 1, pp. 159-177, 2015.

[6] X. Hao, Y. Wei, K. Yang et al., "Anisotropy of crack initiation strength and damage strength of coal reservoirs," Petroleum Exploration and Development, vol. 48, no. 1, pp. 243-255, 2021.

[7] A. Ozguven and Y. Ozcelik, "Effects of high temperature on physico-mechanical properties of Turkish natural building stones," Engineering Geology, vol. 183, pp. 127-136, 2014.

[8] T. Yin, X. Li, W. Cao, and K. Xia, "Effects of thermal treatment on tensile strength of Laurentian granite using Brazilian test," Rock Mechanics and Rock Engineering, vol. 48, no. 6, pp. 2213-2223, 2015.

[9] M. Oda, "Modern developments in rock structure characterization," Comprehensive Rock Engineering, vol. 1, pp. 185-200, 1993.

[10] X. Xu and Q. Liu, "A preliminary study on basic mechanical properties for granite at high temperature," Chinese Journal of Geotechnical Engineering, vol. 22, no. 3, pp. 332-335, 2000.

[11] R. D. Dwivedi, R. K. Goel, V. V. R. Prasad, and A. Sinha, "Thermo-mechanical properties of Indian and other granites," International Journal of Rock Mechanics and Mining Sciences, vol. 96, no. 6, pp. 2383-2391, 2005.

[12] T. Hong, T. Kempka, and N. Xu, "Physical properties of sandstones after high temperature treatment," Rock Mechanics and Rock Engineering, vol. 45, no. 6, pp. 1113-1117, 2012.

[13] T. Y. Guo, L. N. Y. Wong, and Z. J. Wu, "Microcracking behavior transition in thermally treated granite under mode I loading," Engineering Geology, vol. 282, Article ID 105992, 2021.

[14] J. Rutqvist, B. Freifeld, K.-B. Min, D. Elsworth, and Y. Tsang, "Analysis of thermally induced changes in fractured rock permeability during 8 years of heating and cooling at the yucca mountain drift scale test," International Journal of Rock Mechanics and Mining Sciences, vol. 45, no. 8, pp. 1373-1389, 2008.
[15] J. Rutqvist, D. Barr, R. Datta et al., "Coupled thermal-hydrological-mechanical analyses of the yucca mountain drift scale test-comparison of field measurements to predictions of four different numerical models," International Journal of Rock Mechanics and Mining Sciences, vol. 42, no. 5-6, pp. 680-697, 2005.

[16] Z. Zhu, H. Tian, N. Dong, and B. Dou, "Experimental study of physico-mechanical properties of heat-treated granite by water cooling," Rock and Soil Mechanics, vol. 39, no. s2, pp. 169-176, 2018.

[17] B. Xi and Y. Zhao, "Experimental research on mechanical properties of water-cooled granite under high temperatures within $600^{\circ} \mathrm{C}$," Chinese Journal of Rock Mechanics and Engineering, vol. 29, no. 5, pp. 892-898, 2010.

[18] T. D. Rathnaweera, P. G. Ranjith, X. Gu et al., "Experimental investigation of thermomechanical behaviour of clay-rich sandstone at extreme temperatures followed by cooling treatments," International Journal of Rock Mechanics and Mining Sciences, vol. 107, pp. 208-223, 2018.

[19] F. Zhang, Y. Zhang, Y. Yu, D. Hu, and J. Shao, "Influence of cooling rate on thermal degradation of physical and mechanical properties of granite," International Journal of Rock Mechanics and Mining Sciences, vol. 129, Article ID 104285, 2020.

[20] C. E. Fairhurst and J. A. Hudson, "Discussion," International Journal of Rock Mechanics and Mining Sciences, vol. 36, no. 3, pp. 279-289, 1999.

[21] J. A. Hudson and J. P. Harrison, Engineering Rock Mechanics I, Pergamon Press, Oxford, UK, 2000.

[22] X. Xu, F. Gao, X. Shen, and C.-H. Jin, "Research on mechanical characteristics and micropore structure of granite under high-temperature," Rock and Soil Mechanics, vol. 31, no. 6 , pp. 1752-1758, 2010.

[23] F. E. Heuze, "High-temperature mechanical, physical and thermal properties of granitic rocks-a review," International Journal of Rock Mechanics and Mining Sciences \& Geomechanics Abstracts, vol. 20, no. 1, pp. 3-10, 1983.

[24] S. Du, H. Liu, H. Zhi, and H. Chen, "Testing study on mechanical properties of post-high-temperature granite," Chinese Journal of Rock Mechanics and Engineering, vol. 23, no. 14, pp. 2359-2364, 2004.

[25] M. Lin, Thermophysical Properties and Engineering Applications of Rocks, Chongqing University Press, Chongqing, China, 1991.

[26] X. Xu, F. Gao, Y. Gao, and H. Xie, "Effect of high temperatures on the mechanical characteristics and crystal structure of granite," Journal of China University of Mining and Technology, vol. 37, no. 3, pp. 402-406, 2008.

[27] Q. Wu, L. Weng, Y. Zhao, B. Guo, and T. Luo, "On the tensile mechanical characteristics of fine-grained granite after heating/cooling treatments with different cooling rates," Engineering Geology, vol. 253, pp. 94-110, 2019. 